\title{
SEQUENTIAL SUBSTITUTION OF METHYL SIDE GROUP IN NAPTHOQUINONE AND ANTHRAQUINONE TO INVESTIGATE SENSITIVITY OF THE CARBONYL BAND
}

\section{Nabin Kumar Raut and Hari Prasad Lamichhane}

Journal of Institute of Science and Technology

Volume 22, Issue 1, July 2017

ISSN: 2469-9062 (print), 2467-9240 (e)

Editors:

Prof. Dr. Kumar Sapkota

Prof. Dr. Armila Rajbhandari

Assoc. Prof. Dr. Gopi Chandra Kaphle

JIST, 22 (1): 137-146 (2017)

Voltune 22

Issue 1

Jaly 2017

JOURNAL OF INSTITUTE OF

SCIENCE AND TECHNOLOGY

Published by:

Institute of Science and Technology

Tribhuvan University

Kirtipur, Kathmandu, Nepal

Institute of Seience and Technology

Tribhuvan University

Kintipur, Kathmandu, Nepal 


\title{
SEQUENTIAL SUBSTITUTION OF METHYL SIDE GROUP IN NAPTHOQUINONE AND ANTHRAQUINONE TO INVESTIGATE SENSITIVITY OF THE CARBONYL BAND
}

\author{
Nabin Kumar Raut and Hari Prasad Lamichhane* \\ Central Department of Physics, Tribhuvan University, Kirtipur, Nepal \\ Corresponding E-mail: hlamichhane1@gmail.com
}

\begin{abstract}
In this work, we have added methyl side group (s) on quinone and aromatic ring carbon positions of 1 , 4-naphthoquinone (NQ) and on aromatic ring carbon positions of 1, 4-anthraquinone (AQ) in sequential increasing order to check sensitivity of the carbonyl band. In NQ, we observed that the aromatic substitution is more sensitive than the quinonic substitution. In fact, the sequential addition of $\mathrm{CH}_{3}$ on the quinone ring $\mathrm{C}_{5}$ and $\mathrm{C}_{6}$ positions lead into the systematic lowering of the band and such lowering is in average of $5 \mathrm{~cm}^{-1}$ per methyl group. On the other hand, addition on the aromatic ring $\mathrm{C}_{7}, \mathrm{C}_{8}, \mathrm{C}_{9}$, and $\mathrm{C}_{10}$ positions resulted in mix effect. Indeed, they produce two types of carbonyl band, which are couple and uncouple. For further exploration of the sensitivity of the carbonyl band, we put single or two methyl group (s) on $\mathrm{C}_{7}, \mathrm{C}_{8}$, $\mathrm{C}_{9}$, and $\mathrm{C}_{10}$ carbon positions producing four or six NQ model molecules. We concluded that the carbonyl intense bands are more sensitive, split up, to the aromatic ring methyl substitution at $\mathrm{C}_{7}$ or $\mathrm{C}_{10}$ position. Furthermore, in AQ couple mode of $\mathrm{C}=\mathrm{O}$ vibration was observed and no splitting of the band was seen on sequential $\mathrm{CH}_{3}$ addition.
\end{abstract}

Keywords: Carbonyl band, IR spectra, Naphthoquinone, Anthraquinone, Photosynthesis.

\section{INTRODUCTION}

Photosynthesis has special connection with human being, since it is essential for our survival. During this process, carbon dioxide $\left(\mathrm{CO}_{2}\right)$ is used up and oxygen $\left(\mathrm{O}_{2}\right)$ is evolved as a byproduct (as shown in relation below).

$6 \mathrm{CO}_{2}+12 \mathrm{H}_{2} \mathrm{O}+18 \mathrm{ATP}+12 \mathrm{NADP} \rightarrow$

$\mathrm{C}_{6} \mathrm{H}_{12} \mathrm{O}_{6}+18 \mathrm{ADP}+18 \mathrm{P}_{\mathrm{i}}+12 \mathrm{NADP}^{+}+12 \mathrm{H}^{+}+6 \mathrm{O}_{2}$

$(\mathrm{Ke}, 2001)$

On the other hand, we inhale oxygen $\left(\mathrm{O}_{2}\right)$ and exhale carbondioxide $\left(\mathrm{CO}_{2}\right)$ (as shown in relation below).

$\mathrm{C}_{6} \mathrm{H}_{12} \mathrm{O}_{6}+6 \mathrm{O}_{2} \rightarrow 6 \mathrm{CO}_{2}+6 \mathrm{H}_{2} \mathrm{O}+\mathrm{ATP}$

In this ways, waste of one becomes essential usage for other. The photosynthesis process takes away something that is noxious $\left(\mathrm{CO}_{2}\right)$ and gives us something precious $\left(\mathrm{O}_{2}\right)(\mathrm{Ke}, 2001)$. Quinones play vital role to complete the photosynthesis process. Quinone serves as a coupler of electron and proton transfers in vivo in energy-transducing membrane for respiration and photosynthesis (Ke, 2001; Patai, 1974; Trumpower, 1982; Okamura et al., 2000).
In photosystem I (PS I) phylloquinone (vitamin $\mathrm{K}_{1}$ ), a type of naphthoquinone, occupies $\mathrm{A}_{1}$ bindingsite. Moreover, Quinone can be used as vitamin, anticancer drugs, and dyes (Ke, 2001; Wakil, 1970; Guin et al., 2011).

Furthermore, in this work we observed normal mode vibrational frequencies of both naphthoquinone and anthraquinone model molecules. The normal modes of vibration (or normal vibration) is defined as a molecular motion in which all the atoms oscillate with the same frequency and pass through their equilibrium positions simultaneously (Banwell et al., 1999).

The $\mathrm{N}$ non-linear molecules have, Total normal modes of vibrations $=3 \mathrm{~N}-6$, Bond-stretching mode $=\mathrm{N}-1$, Bending modes $=2 \mathrm{~N}-5$. Since molecular vibrational energy differences lies in the infrared region, the infrared (IR) is useful spectroscopy to monitor vibrational energy level in molecules. Specific group of atoms in the molecule absorb at different but definite frequency region (Banwell et al., 1999; Lamichhane, 2011). Here, we have chosen spectra in the region 1800-1550 or 1800$1600 \mathrm{~cm}^{-1}$ because experimentally detectable carbonyl $(\mathrm{C}=\mathrm{O})$ and $\mathrm{C}=\mathrm{C}$ vibrations lie in this region 
(Banwell et al.,1999; Coates, 2000; Socrates, 2004; Bellamy, 1980). The set of normal modes of a pure chemical compound in a given environment is unique. For this reason, the IR spectrum, which is representative of the normal mode structure of a molecule, is unique identifier of a specific molecule in a specific environment and provides a "fingerprint" of the molecule (s) (Lamichhane, 2011).

Nonella \& Brandli (Nonella et al., 1996) did investigation on methoxy substituted pbenzoquinone. They analyzed 2-methoxy-1, 4benzoquinone, 2, 3-dimethoxy-1, 4-benzoquinone, 2, 3-dimethoxy-5, 6-dimethyl-1, 4-benzoquinone (MQ), 2, 3-dimethoxy-5-methyl-6-phytyl-1, 4benzoquinone (UQ), 2, 3-dimothoxy-6-ally-1, 4benzoquinone by substituting different side groups on quinone ring carbon positions of p-benzoquinone to study whether calculated vibrational spectrum depend on the nature of the substituent. Similarly, Bandaranayake et al. (2006) had modified phylloquinone (PhQ) into PhNQ (methyl less PhQ). In addition, Hucke et al. determined the binding free energy and charge recombination rate from $\mathrm{Q}_{\mathrm{A}}{ }^{-}$to $\mathrm{D}^{+}\left(\mathrm{K}_{\mathrm{AD}}\right)$ of 29 different 1, 4-naphthoquinone derivatives with systematically altered structures to study the binding mode of these quinones to the $\mathrm{Q}_{\mathrm{A}}$ binding site (Hucke et al., 2002). These researches have inspiration our work.

\section{COMPUTATIONAL METHOD}

By using hybrid density functional theory (DFT) method we have done geometrical optimization and vibrational frequency calculations, employing B3LYP functional and the 6-31G+(d) method within Gaussian 03 (Frisch et al., 2004). All the spectra are generated from the calculated stick spectra by convolving with Gaussian function of wavenumber $4 \mathrm{~cm}^{-1}$ to produce more realistic looking spectra.

\section{RESULTS AND DISCUSSION}

In order to check sensitivity of the carbonyl band by sequential substitution of methyl group we have taken two different types of quinones, which are naphthoquinone and anthraquinone. All naphthoquinones have a quinone and an aromatic ring, whereas all anthraquinones contain two aromatic rings and single quinone ring. Hence, for similar side group only feature that distinguish between these two families is an aromatic ring.

\section{Naphthoquinone}

Methyl substitution on NQ at quinonic ring carbon positions:

Figure 1 shows structure and numbering of NQ, MNQ and DMNQ. They all belong to class of 1, 4naphthoquinone family. The MNQ has single methyl group at $\mathrm{C}_{5}$ positions and theDMNQ has two such groups at $\mathrm{C}_{5}$ and $\mathrm{C}_{6}$ positions on the quinone ring. Here, NQ is taken as a reference molecule. The aromatic and quinone ring are presented in all three of them. Going from NQ to MNQ to DMNQ number of the methyl group are in the sequential order of 0,1 and 2 .
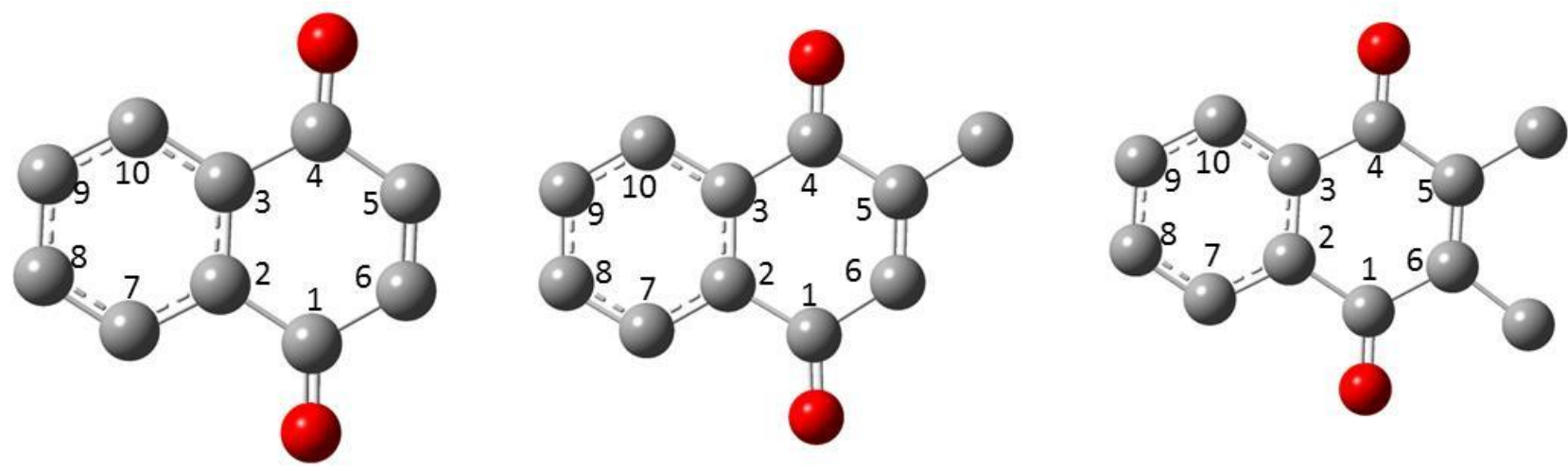

Fig.1. Structure and numbering for 1, 4-naphthoquinone (NQ), 5-methyl-1, 4-naphthoquinone (MNQ), and 5, 6-dimethyl-1, 4-naphthoquinone (DMNQ).

Calculated IR absorption spectra of NQ, MNQ and DMNQ are shown in the figure 2 and their mode assignment is enlisted in Table 1 . Here, we have chosen spectra in the region 1800-1550 $\mathrm{cm}^{-1}$ because experimentally detectable carbonyl $(\mathrm{C}=\mathrm{O})$ and $\mathrm{C}=\mathrm{C}$ vibrations lie in this region (Banwell et al., 1999; Coates, 2000; Socrates, 2004; Bellamy, 1980). In the spectra, we have observed three 
bands, one intense and two weak. The intense band is produced due to couple carbonyl mode of vibration, whereas the two weaker bands are predominantly due to $\mathrm{C}_{5}=\mathrm{C}_{6}$ stretching and partially double aromatic ring vibration. Actually, the weaker band has at least $82 \%$ less intensity than the intense band.

In this paper, our goal is to discuss about effect of methyl substitution on the carbonyl band. Thus, the intense band of NQ/MNQ/DMNQ due to coupled carbonyl modes of vibration was observed at $1735 / 1730 / 1721 \mathrm{~cm}^{-1}$. Indeed, the sequential addition of the methyl group resulted into the systematic lowering in the intense band and such lowering was in average of $5 \mathrm{~cm}^{-1}$ per methyl group. Importantly, in all three quinones similar nature of carbonyl band (couple) was seen. We know that, the normal mode vibrational frequencies depend upon the strength of the bond between two atoms and reduced mass of the molecule (Banwell et al., 1999). In fact, how much effect on the charge distribution of the functional group due to the presence of particular side group is reflected upon change in its corresponding frequency? In NQ, electronic charge distribution homogeneously distributed over two $\mathrm{C}=\mathrm{O}$ modes give rise to couple mode of carbonyl vibration. Similarly, presence of one (in MNQ) or two (in DMNQ) methyl group at $\mathrm{C}_{5}$ or $\mathrm{C}_{5}$ and $\mathrm{C}_{6}$ positions is not sufficient enough to make asymmetric distribution of charge among both $\mathrm{C}=\mathrm{O}$ groups so that it can split the band. In addition, the quinonic $\mathrm{C}_{5}=\mathrm{C}_{6}$ mixed slightly with symmetric $\mathrm{C}=\mathrm{O}$ stretching vibration of $\mathrm{NQ}, \mathrm{MNQ}$ and DMNQ occur at 1671, 1683, and $1670 \mathrm{~cm}^{-1}$ respectively and their aromatic partially double $\mathrm{C}=\mathrm{C}$ mode was seen at single frequency $1640 \mathrm{~cm}^{-1}$.

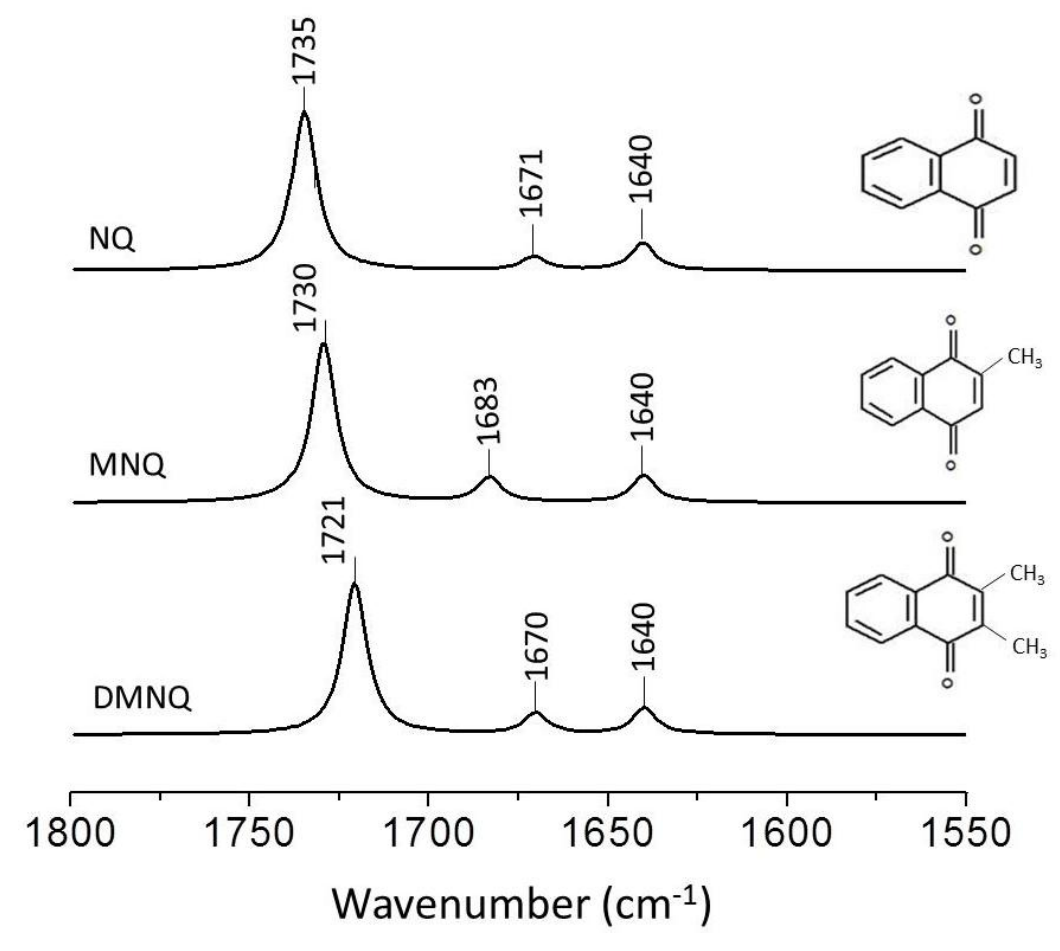

Fig. 2. Calculated IR absorption spectra of NQ, MNQ and DMNQ in gas phase.

Table 1. Mode Assignments (in $\mathrm{cm}^{-1}$ ) for NQ, MNQ, and DMNQ

\begin{tabular}{|l|l|l|l|}
\hline Modes & NQ & MNQ & DMNQ \\
\hline$v(\mathrm{C}=\mathrm{O})$, as & $1735(380)$ & $1730(391)$ & $1721(372)$ \\
\hline$v\left(\mathrm{C}_{5}=\mathrm{C}_{6}\right), \mathrm{q}$ & $1671(35)$ & $1683(62)$ & $1670(52)$ \\
\hline$v(\mathrm{C}=\mathrm{C})^{*}, \mathrm{a}$ & $1640(69)$ & $1640(68)$ & $1640(66)$ \\
\hline
\end{tabular}

Abbreviations: as, asymmetric; q, quinone ring; *, bond is partially double; a, aromatic ring. 
Methyl substitution on NQ at aromatic ring carbon positions:

Figure 3 shows the structure and numbering of five methyl substituted naphthoquinones, which are $\mathrm{NQ}, \mathrm{NQ}_{7}, \mathrm{NQ}_{7,8}, \mathrm{NQ}_{7,8,9}$, and $\mathrm{NQ}_{7,8,9,10}$. The NQ molecule was taken as a reference molecule and methyl group was added on it in sequential manner as 1, 2, 3, and 4. Naming of the molecules were done according to position and number of the methyl group. For example, $\mathrm{NQ}_{7}$ refers to the molecule that has single methyl group at $\mathrm{C}_{7}$ position. Similarly, $\mathrm{NQ}_{7,8}$ refers to the naphthoquinone that has two methyl groups at $\mathrm{C}_{7}$ and $\mathrm{C}_{8}$ positions. In fact, the number in the subscript represent position of the methyl group and total count of such number gives total substitution of the group.
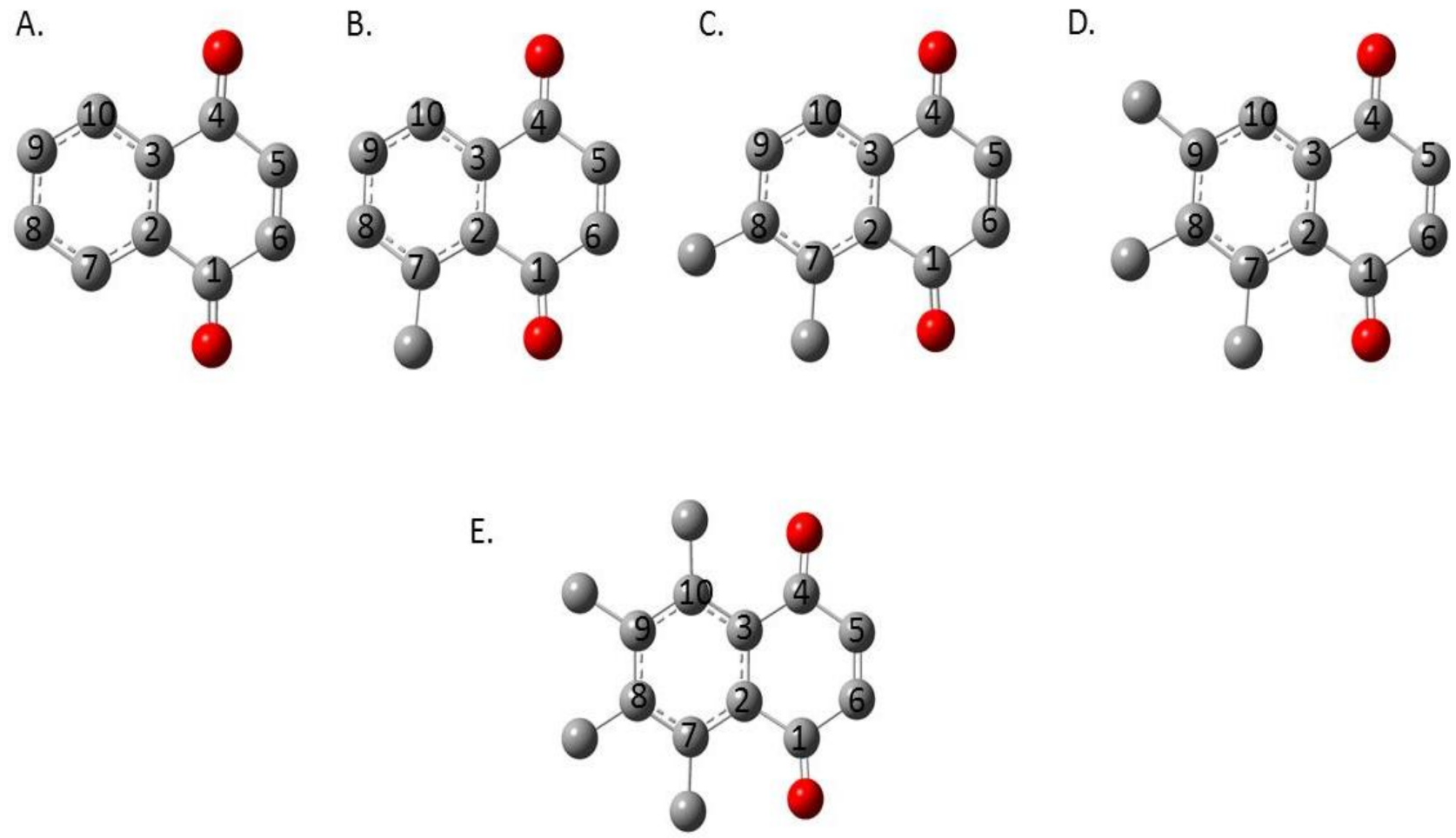

Fig. 3. Structure and numbering for (A) 1, 4-naphthoquinone (NQ), (B) 7-methyl-1, 4-naphthoquinone $\left(N Q_{7}\right),(C)$ 7, 8-dimethyl-1, 4-naphthoquinone $\left(N Q_{7,8}\right),(D)$ 7, 8, 9-trimethyl-1, 4-naphthoquinone $\left(N Q_{7,8,9}\right)$, and $(E) 7,8,9$, 10-tetramethyl-1, 4-naphthoquinone $\left(N Q_{7,8,9,10}\right)$.

Figure 4 shows the calculated IR absorption spectra of five different naphthoquinones $\left(\mathrm{NQ}, \mathrm{NQ}_{7}, \mathrm{NQ}_{7,8}\right.$, $\mathrm{NQ}_{7,8,9}$, and $\mathrm{NQ}_{7,8,9,10}$ ) and their prominent modes are enlisted in table 2. In the spectra, two different nature of carbonyl band were observed: couple and uncouple. The NQ and $\mathrm{NQ}_{7,8,9,10}$ have an intense couple carbonyl band, respectively, at 1735 and $1714 \mathrm{~cm}^{-1}$. On the other hand, the sequential increment of methyl group from $\mathrm{C}_{7}, \mathrm{C}_{8}$, and $\mathrm{C}_{9}$ resulted into uncoupling of the band. On such splitting the couple $\mathrm{C}=\mathrm{O}$ mode separated into $\mathrm{C}_{1}=\mathrm{O}$ and $\mathrm{C}_{4}=\mathrm{O}$ stretching modes of vibration and were 8 or $9 \mathrm{~cm}^{-1}$ apart. Among $\mathrm{C}_{1}=\mathrm{O}$ and $\mathrm{C}_{4}=\mathrm{O}$ modes, former one goes to the lower frequency and latter one remains on the upper frequency. The $\mathrm{C}_{1}=\mathrm{O}$ mode not only goes to the lower frequency but its intensity also reduces to one-fourth than $\mathrm{C}_{4}=\mathrm{O}$ mode. In fact, $\mathrm{C}_{1}=\mathrm{O}$ mode of $\mathrm{NQ}_{7}, \mathrm{NQ}_{7,8}$ and $\mathrm{NQ}_{7,8,9}$ were found at 1723,1721 , and $1719 \mathrm{~cm}^{-1}$ respectively and their $\mathrm{C}_{4}=\mathrm{O}$ mode was found respectively, at 1732,1729 , and $1728 \mathrm{~cm}^{-1}$. In addition, the quinonic $\mathrm{C}_{5}=\mathrm{C}_{6}$ mixed slightly with symmetric $\mathrm{C}=\mathrm{O}$ stretching vibration of $\mathrm{NQ}, \mathrm{NQ}_{7}$, $\mathrm{NQ}_{7,8}, \mathrm{NQ}_{7,8,9}$ and $\mathrm{NQ}_{7,8,9,10}$ occurred, respectively, at $1671,1678,1679,1678$, and $1684 \mathrm{~cm}^{-1}$ and their aromatic partially double $\mathrm{C}=\mathrm{C}$ mode was seen respectively, at 1640, 1634, 1623, 1624, and $1580 \mathrm{~cm}^{-1}$. 


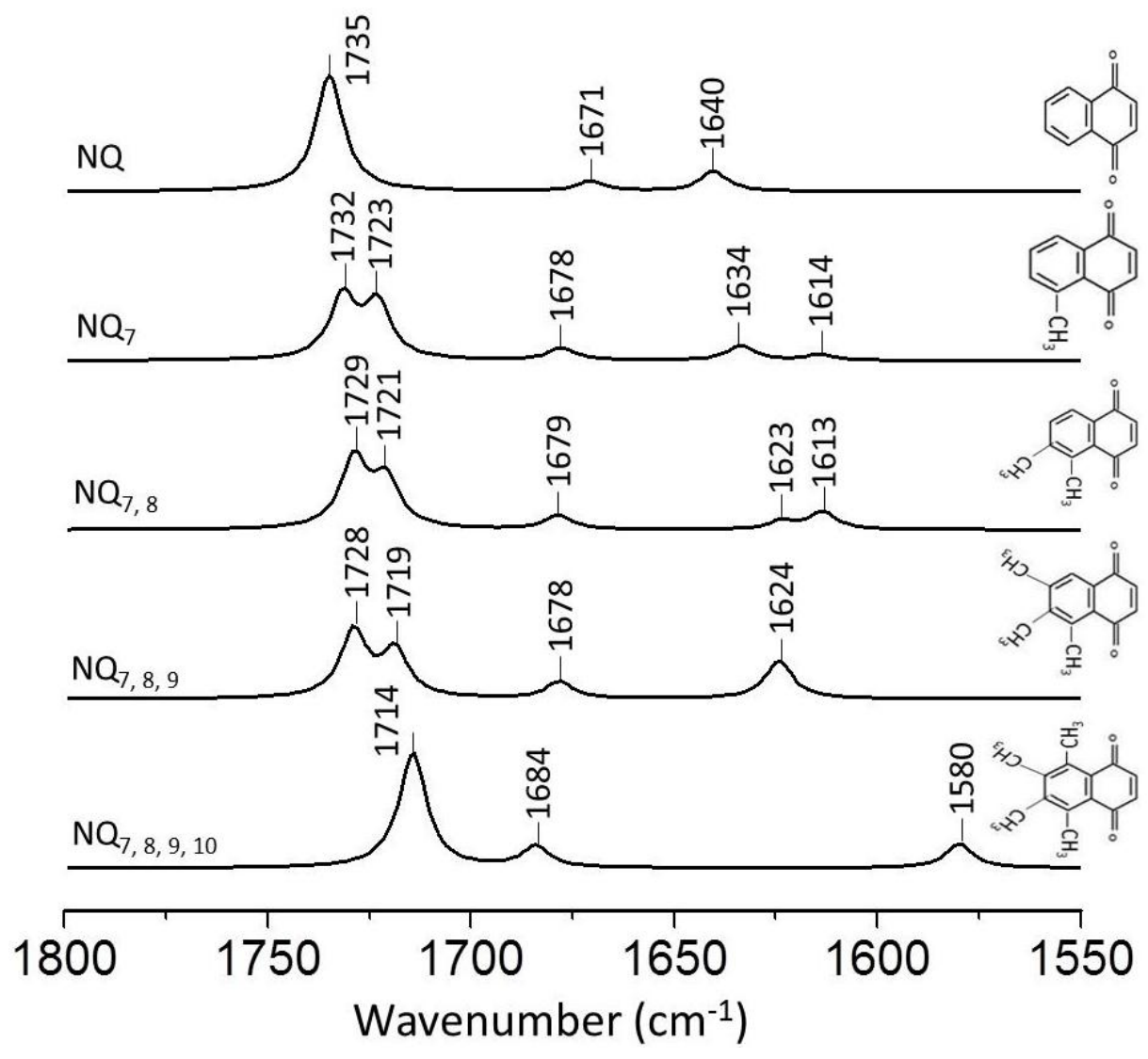

Fig. 4. Calculated IR absorption spectra of $N Q, N Q_{7}, N Q_{7,8}, N Q_{7,8,9}$, and $N Q_{7,8,9,10}$ in gas phase.

Table 2. Mode Assignments (in $\mathrm{cm}^{-1}$ ) for $\mathrm{NQ}_{7}, \mathrm{NQ}_{7,8}, \mathrm{NQ}_{7,8,9}$, and $\mathrm{NQ}_{7,8,9,10}$

\begin{tabular}{|l|l|l|l|l|l|}
\hline Modes & $\mathbf{N Q}$ & $\mathbf{N Q}_{7}$ & $\mathbf{N Q}_{7,8}$ & $\mathbf{N Q}_{7,8,9}$ & $\mathbf{N Q}_{7,8,9,10}$ \\
\hline$v(\mathrm{C}=\mathrm{O})$, as & $1735(380)$ & & & & $1714(387)$ \\
\hline$v\left(\mathrm{C}_{1}=\mathrm{O}\right)$ & & $1723(165)$ & $1721(165)$ & $1719(160)$ & \\
\hline$v\left(\mathrm{C}_{4}=\mathrm{O}\right)$ & & $1732(213)$ & $1729(237)$ & $1728(227)$ & \\
\hline$v\left(\mathrm{C}_{5}=\mathrm{C}_{6}\right), \mathrm{q}$ & $1671(35)$ & $1678(41)$ & $1679(49)$ & $1678(56)$ & $1684(72)$ \\
\hline$v(\mathrm{C}=\mathrm{C})^{*}$, a & $1640(69)$ & $1634(50)$ & $1623(28)$ & $1624(129)$ & $1580(82)$ \\
\hline
\end{tabular}

Abbreviations: as, asymmetric; q, quinone ring; *, bond is partially double; a, aromatic ring.

Upon sequential substitution of methyl group on aromatic ring, we were able to observe that the carbonyl band is sensitive to the certain substitutions. For deeper understanding, we alternatively added single methyl group at four different carbon positions of the ring. Figure 5 shows the structure and numbering of $\mathrm{NQ}_{7}, \mathrm{NQ}_{8}$, $\mathrm{NQ}_{9}$, and $\mathrm{NQ}_{10}$. We gave name of the $\mathrm{NQ}$ according to the position of such substitution in the ring. For example, $\mathrm{NQ}_{7}$ refers to the naphthoquinone that has the methyl group at $\mathrm{C}_{7}$ position of the aromatic ring. 

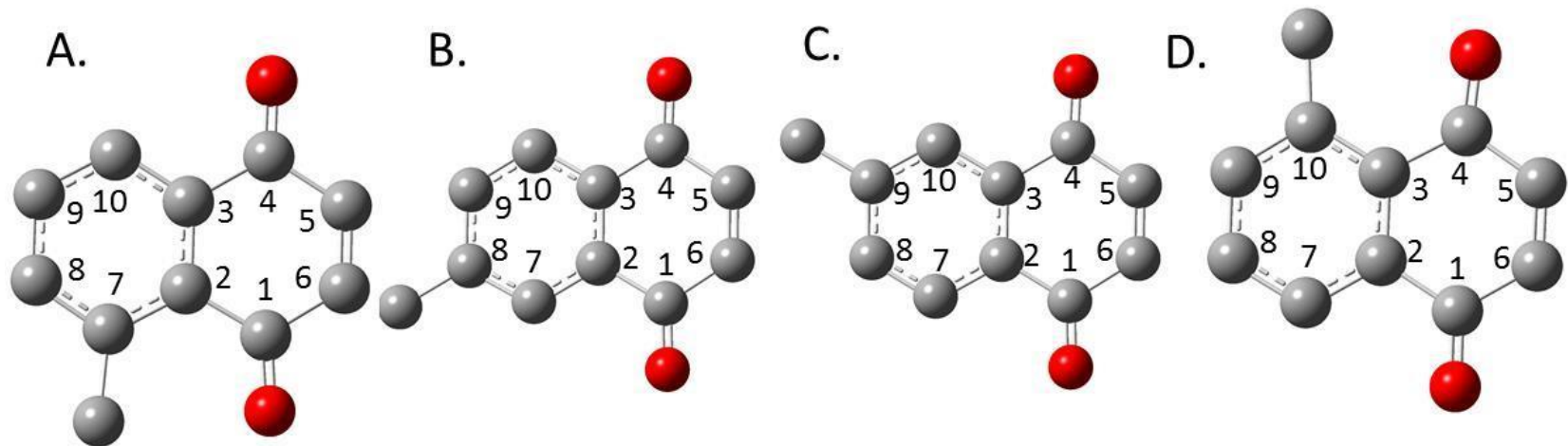

Fig. 5. Structure and numbering for (A) 7-methyl-1, 4-naphthoquinone $\left(N Q_{7}\right),(B) 8$-methyl-1, 4-naphthoquinone $\left(N Q_{8}\right)$, (C) 9-methyl-1, 4-naphthoquinone $\left(N Q_{9}\right)$, and (D) 10-methyl-1, 4naphthoquinone $\left(N Q_{10}\right)$.

Calculated IR spectra of four different 1, 4naphthoquinones $\left(\mathrm{NQ}_{7}, \mathrm{NQ}_{8}, \mathrm{NQ}_{9}\right.$, and $\left.\mathrm{NQ}_{10}\right)$ is shown in the figure 6 . and their mode assignment is enlisted in table 3. Here, $\mathrm{NQ}_{7}, \mathrm{NQ}_{8}, \mathrm{NQ}_{9}$, and $\mathrm{NQ}_{10}$ have envisioned two different natures of carbonyl bands as shown in Fig. 6: couple and uncouple. In case of $\mathrm{NQ}_{8} \& \mathrm{NQ}_{9}$, highly active IR band due to coupled $\mathrm{C}=\mathrm{O}$ vibration was observed at $1734 \mathrm{~cm}^{-1}$. However, in $\mathrm{NQ}_{7} \& \mathrm{NQ}_{10}$ this band split into $\mathrm{C}_{1}=\mathrm{O}$ and $\mathrm{C}_{4}=\mathrm{O}$ stretching mode of vibration. For $\mathrm{NQ}_{7}$ $\mathrm{C}_{1}=\mathrm{O}$ stretching mode was found at lower frequency $\left(1723 \mathrm{~cm}^{-1}\right)$ having intensity $22 \%$ less than $\mathrm{C}_{4}=\mathrm{O}$ mode, which occurred at higher frequency $\left(1732 \mathrm{~cm}^{-1}\right)$. In contrast, for $\mathrm{NQ}_{10} \mathrm{C}_{1}=\mathrm{O}$ stretching mode remained in the upper frequency (at $1731 \mathrm{~cm}^{-1}$ ) and $\mathrm{C}_{4}=\mathrm{O}$ mode goes down to the lower frequency (at $1723 \mathrm{~cm}^{-1}$ ) and intensity of former mode was $12 \%$ more than the latter.
The normal mode vibrational frequencies depend directly upon the electronic charge distribution. Here, the split carbonyl band charge was nonhomogeneously distributed over two $\mathrm{C}=\mathrm{O}$ bonds compared to that of coupled carbonyl band. Among $\mathrm{C}_{1}=\mathrm{O}$ and $\mathrm{C}_{4}=\mathrm{O}$ mode, which one goes down on splitting is determined by the position of substituted methyl group. The methyl group affects the charge distribution of nearest neighbor $\mathrm{C}=\mathrm{O}$ bond pushes the band to lower frequency, while the opposite $\mathrm{C}=\mathrm{O}$ bond remain undisturbed at upper frequency. In addition, the quinonic $\mathrm{C}_{5}=\mathrm{C}_{6}$ mixed slightly with symmetric $\mathrm{C}=\mathrm{O}$ stretching vibration of $\mathrm{NQ}_{8} \& \mathrm{NQ}_{9}$ occured at a same frequency $1670 \mathrm{~cm}^{-1}$ and of $\mathrm{NQ}_{7} \& \mathrm{NQ}_{10}$ at $1678 \mathrm{~cm}^{-1}$ and the aromatic partially double $\mathrm{C}=\mathrm{C}$ mode of $\mathrm{NQ}_{8}$ and $\mathrm{NQ}_{9} / \mathrm{NQ}_{7}$ and $\mathrm{NQ}_{10}$ seen at $1647 / 1634 \mathrm{~cm}^{-1}$.

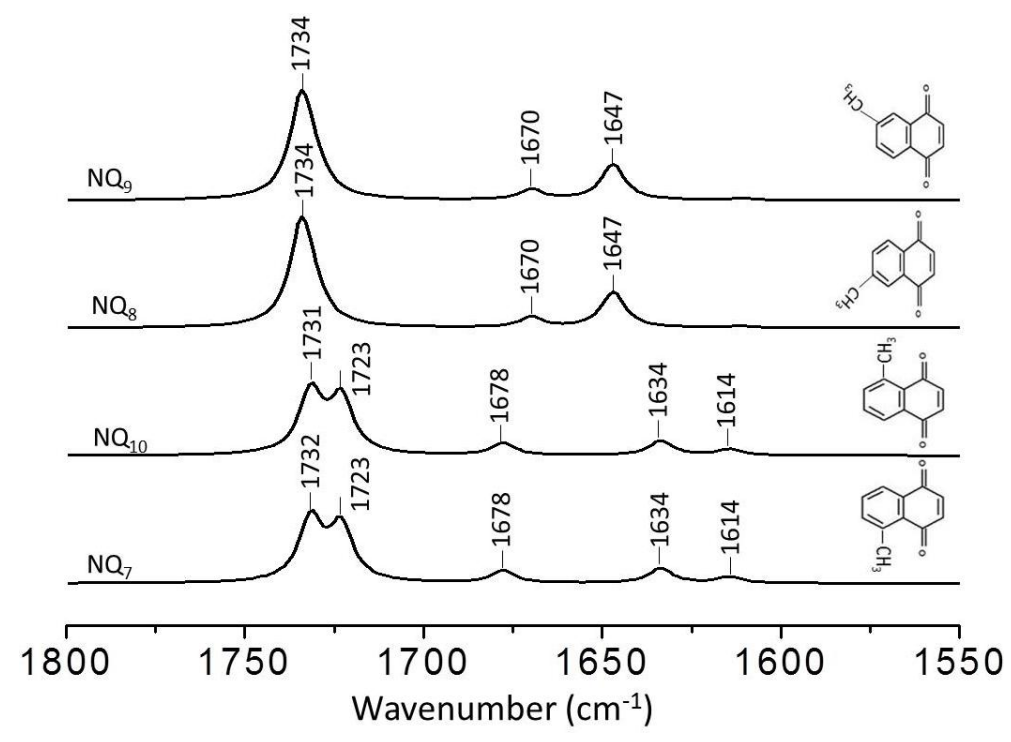

Fig. 6. Calculated IR absorption spectra of $N Q_{7}, N Q_{8}, N Q_{9}$ and $N Q_{10}$ in gas phase. 
Table 3. Mode Assignments (in $\mathrm{cm}^{-1}$ ) for $\mathrm{NQ}_{7}, \mathrm{NQ}_{8}, \mathrm{NQ}_{9}$, and $\mathrm{NQ}_{10}$.

\begin{tabular}{|l|l|l|l|l|}
\hline Modes & $\mathbf{N Q}_{7}$ & $\mathbf{N Q}_{\mathbf{8}}$ & $\mathbf{N Q}_{\mathbf{9}}$ & $\mathbf{N Q}_{\mathbf{1 0}}$ \\
\hline$v(\mathrm{C}=\mathrm{O})$, as & & $1734(350)$ & $1734(343)$ & \\
\hline$v\left(\mathrm{C}_{1}=\mathrm{O}\right)$ & $1723(165)$ & & & $1731(213)$ \\
\hline$v\left(\mathrm{C}_{4}=\mathrm{O}\right)$ & $1732(213)$ & & & $1723(188)$ \\
\hline$v\left(\mathrm{C}_{5}=\mathrm{C}_{6}\right), \mathrm{q}$ & $1678(41)$ & $1670(34)$ & $1670(34)$ & $1678(41)$ \\
\hline$v(\mathrm{C}=\mathrm{C})^{*}, \mathrm{a}$ & $1634(50)$ & $1647(120)$ & $1647(121)$ & $1634(51)$ \\
\hline
\end{tabular}

Abbreviations: as, asymmetric; q, quinone ring; *, bond is partially double; a, aromatic ring.

For further exploration of sensitivity of the carbonyl band, we have added two methyl groups on $\mathrm{C}_{7}, \mathrm{C}_{8}, \mathrm{C}_{9}$, and $\mathrm{C}_{10}$ positions of NQ obtaining six model molecules. Figure 7 shows their structure and numbering. The number in subscript refers to the positions of the methyl groups. For example, $\mathrm{NQ}_{7,8} / \mathrm{NQ}_{7,9} / \mathrm{NQ}_{7,10} / \mathrm{NQ}_{8,9} / \mathrm{NQ}_{8,10} / \mathrm{NQ}_{9,10}$ represents NQ that has methyl groups, respectively, at $\mathrm{C}_{7} \&$ $\mathrm{C}_{8} / \mathrm{C}_{7} \& \mathrm{C}_{9} / \mathrm{C}_{7} \& \mathrm{C}_{10} / \mathrm{C}_{8} \& \mathrm{C}_{9} / \mathrm{C}_{8} \& \mathrm{C}_{10} / \mathrm{C}_{9} \& \mathrm{C}_{10}$ positions.

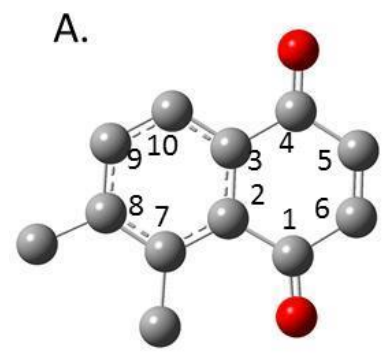

B.
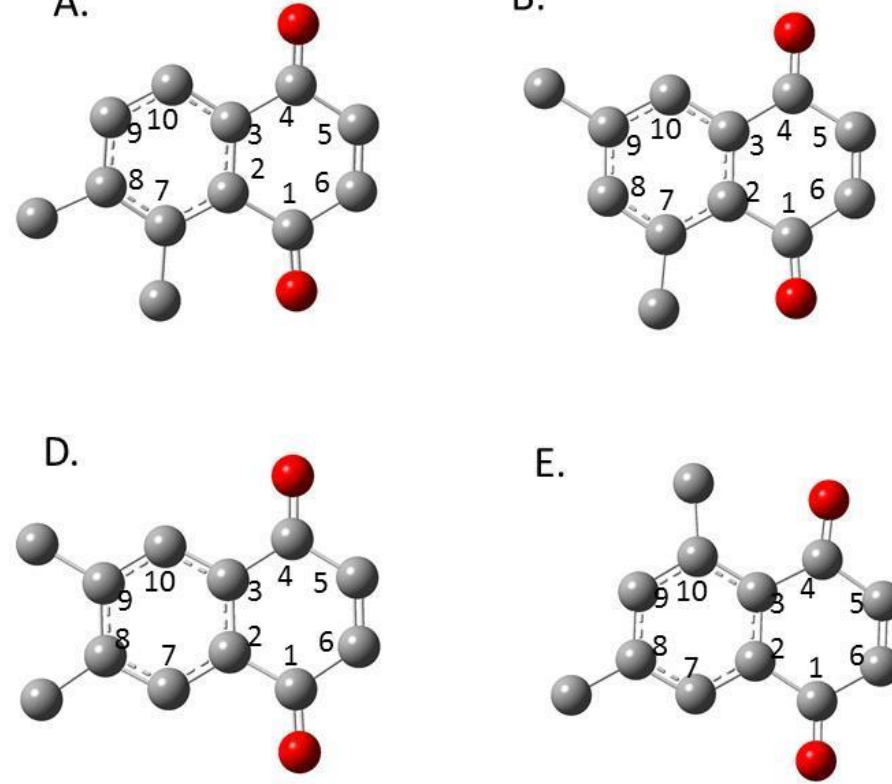

E.

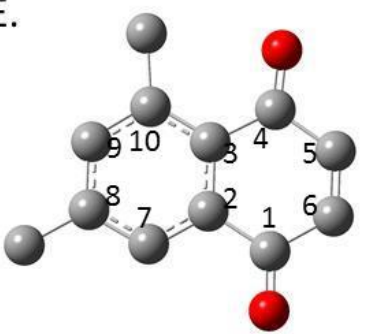

C.

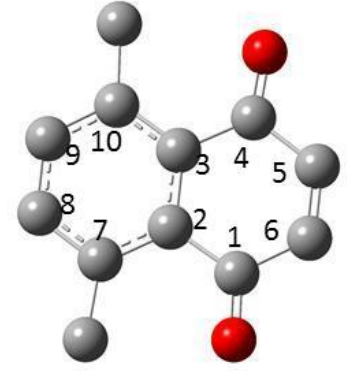

F.

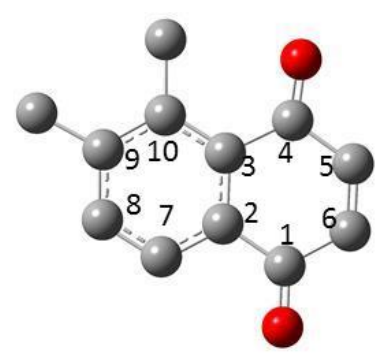

Fig. 7. Structure and numbering for (A) 7, 8-dimethyl-1, 4-naphthoquinone $\left(N Q_{7,8}\right)$, (B) 7, 9-dimethyl-1, 4-naphthoquinone $\left(N Q_{7,9}\right)$, (C) 7, 10-dimethyl-1, 4-naphthoquinone $\left(N Q_{7,10}\right)$, (D) 8, 9-dimethyl-1, 4naphthoquinone $\left(N Q_{8,9}\right)$, $(E) 8,10$-dimethyl-1, 4-naphthoquinone $\left(N Q_{8,10}\right)$, and $(F)$ 9, 10-dimethyl-1, 4naphthoquinone $\left(N Q_{9,10}\right)$.

Calculated IR spectra of six different 1, 4naphthoquinones $\left(\mathrm{NQ}_{7,8,} \mathrm{NQ}_{7,9}, \mathrm{NQ}_{7,10,} \mathrm{NQ}_{8,9}, \mathrm{NQ}_{8}\right.$, ${ }_{10}$, and $\mathrm{NQ}_{9}, 10$ ) is shown in the figure 8. and their mode assignment is enlisted in Table 4 . In the spectra, the intense carbonyl band, main focus of this work of $\mathrm{NQ}_{8,9}$ and $\mathrm{NQ}_{7,10}$ are couple, whereas of $\mathrm{NQ}_{7,8}, \mathrm{NQ}_{7,9}, \mathrm{NQ}_{8,10}$, andNQ $\mathrm{N}_{9,10}$ are uncouple. It further strengthened our conclusion that addition of $\mathrm{CH}_{3}$ group to the $\mathrm{C}_{8}$ and $\mathrm{C}_{9}$ positions of the aromatic ring have insignificant effect on the $\mathrm{C}=\mathrm{O}$ band so that it can split the band. However, addition of two methyl groups, one on $\mathrm{C}_{8}$ or $\mathrm{C}_{9}$ position and other on $\mathrm{C}_{7}$ or $\mathrm{C}_{10}$ position of the aromatic ring has prominent effect on the band. In fact, such substitutions lead to breaking up of the band. Most importantly, presence of methyl groups simultaneously at $\mathrm{C}_{7}$ and $\mathrm{C}_{10}$ positions pushes the band down without its uncoupling. The reason behind it is that the presence of the $\mathrm{CH}_{3}$ groups was unable to bring enough asymmetry on charge among two groups to break the band up and hence lowering down to the same lower frequency was seen. 


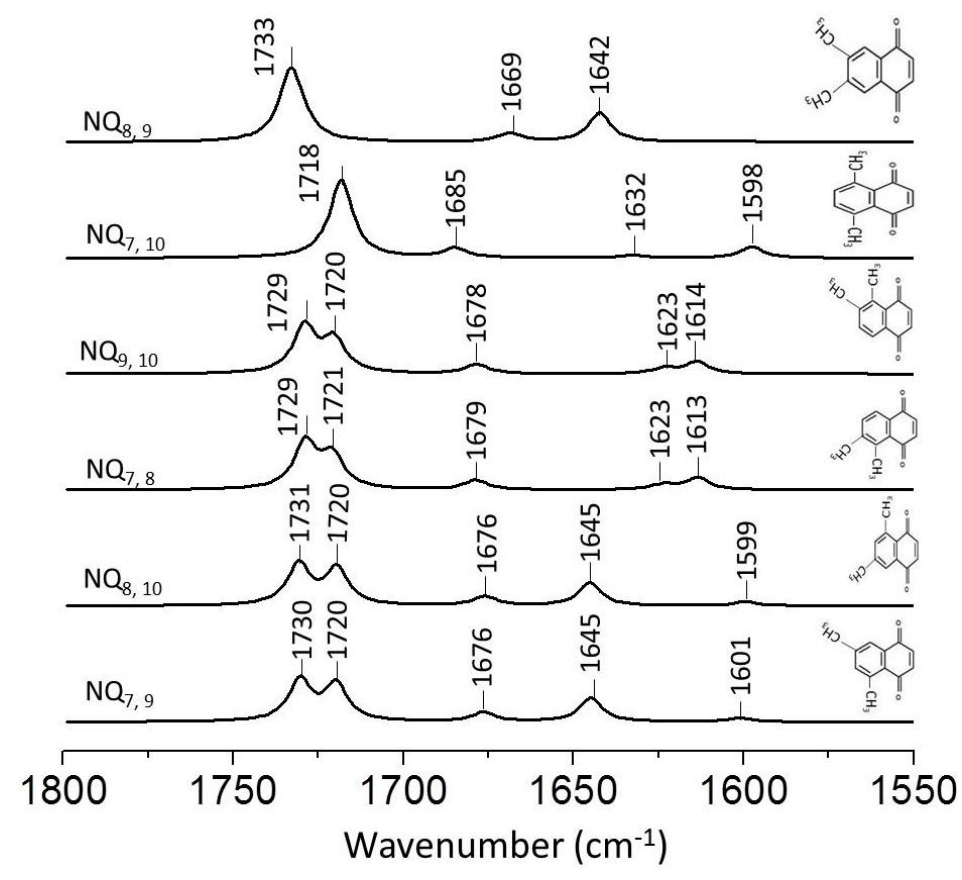

Fig. 8. Calculated IR absorption spectra of $N Q_{7,8}, N Q_{7,9}, N Q_{7,10}, N Q_{8,9}, N Q_{8,10}$, and $N Q_{9,10}$ in gas phase.

Table 4. Mode Assignments (in $\mathrm{cm}^{-1}$ ) for $\mathrm{NQ}_{7,8}, \mathrm{NQ}_{7,9}, \mathrm{NQ}_{7,10}, \mathrm{NQ}_{8,9}, \mathrm{NQ} Q_{8,10}$, and $\mathrm{NQ}_{9,10}$.

\begin{tabular}{|l|l|l|l|l|l|l|}
\hline Modes & $\mathbf{N Q}_{\mathbf{7 , 8}}$ & $\mathbf{N Q}_{\mathbf{7 , 9}}$ & $\mathbf{N Q}_{\mathbf{7}, \mathbf{1 0}}$ & $\mathbf{N Q}_{\mathbf{8 , 9}}$ & $\mathbf{N Q}_{\mathbf{8}, \mathbf{1 0}}$ & $\mathbf{N Q}_{\mathbf{9}, \mathbf{1 0}}$ \\
\hline$v(\mathrm{C}=\mathrm{O})$, as & & & $1718(389)$ & $1733(358)$ & & \\
\hline$v\left(\mathrm{C}_{1}=\mathrm{O}\right)$ & $1721(165)$ & $1720(186)$ & & & $1731(208)$ & $1729(236)$ \\
\hline$v\left(\mathrm{C}_{4}=\mathrm{O}\right)$ & $1729(237)$ & $1730(206)$ & & & $1720(183)$ & $1720(165)$ \\
\hline$v\left(\mathrm{C}_{5}=\mathrm{C}_{6}\right), \mathrm{q}$ & $1679(49)$ & $1676(46)$ & $1685(49)$ & $1669(43)$ & $1676(46)$ & $1678(48)$ \\
\hline$v(\mathrm{C}=\mathrm{C})^{*}, \mathrm{a}$ & $1623(28)$ & $1645(118)$ & $1632(13)$ & $1642(144)$ & $1645(114)$ & $1623(28)$ \\
\hline
\end{tabular}

Abbreviations: as, asymmetric; q, quinone ring; *, bond is partially double; a, aromatic ring Anthraquinone.

Figure 9 shows the structure and numbering scheme for 1, 4-anthraquinone (AQ) family $\left(\mathrm{AQ}, \mathrm{AQ}_{11}\right.$ and
$\left.\mathrm{AQ}_{11,12}\right)$. Each of them has two aromatic and a quinone ring and differ only by side group/groups.
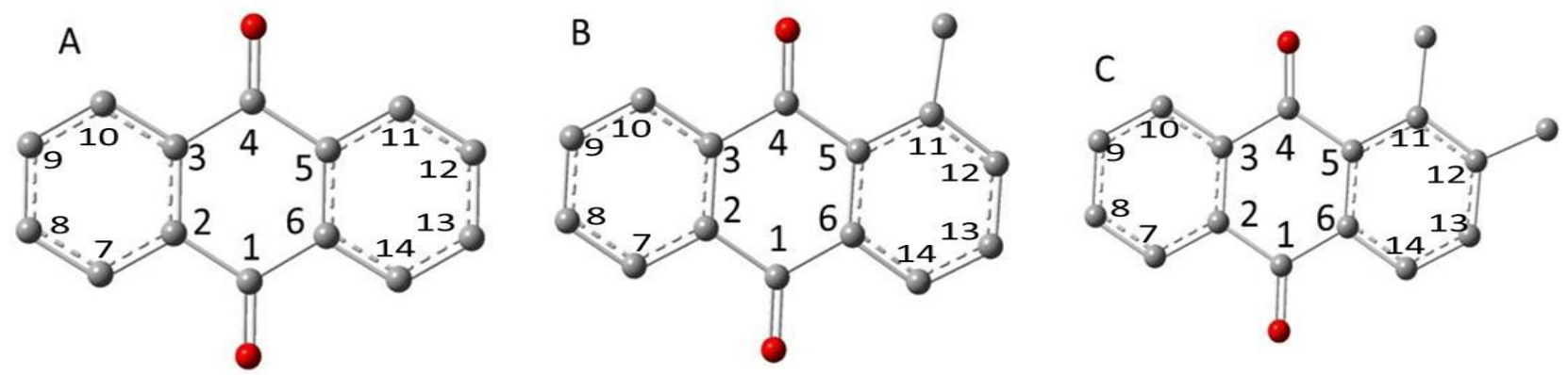

Fig. 9. Structure and numbering for (A) 1, 4-anthraquinone (AQ), (B) 11-methyl-1, 4-anthraquinone $\left(A Q_{11}\right),(C)$ 11, 12-dimethyl-1, 4-anthraquinone $\left(A Q_{11,12}\right)$. 
Calculated IR spectra of three different 1, 4anthraquinones $\left(\mathrm{AQ}, \mathrm{AQ}_{11}\right.$ and $\left.\mathrm{AQ}_{11,12}\right)$ is shown in the Fig. 10. The sequential addition of methyl group on AQ, although leads to the lowering in frequency, has no splitting effect on the intense carbonyl mode of vibration. Such substitution on $A Q$ to get $A Q_{11}$ and $A Q_{11,12}$ lower down frequency of the intense band respectively by 6 and $8 \mathrm{~cm}^{-1}$. In $\mathrm{AQ}$, highly intense band was observed at $1736 \mathrm{~cm}^{-1}$ and cause of this frequency is due to asymmetric $\mathrm{C}=\mathrm{O}$ vibration (Fig. 10.). Besides, weak band at $1637 \mathrm{~cm}^{-1}$ was envisioned and was due to vibration of both aromatic ring mixed with little asymmetric $\mathrm{C}=\mathrm{O}$ vibration. In case of $\mathrm{AQ}_{11}$, highly intense band is observed at $1730 \mathrm{~cm}^{-1}$ which is due to asymmetric $\mathrm{C}=\mathrm{O}$ vibration. In this case, however, weak band is not like that in $\mathrm{AQ}$, single and easily distinguishable, rather than four weak bands almost of same intensity. The band at $1614 / 1641 \mathrm{~cm}^{-1}$ is due to vibration of aromatic ring with/without methyl group. In contrast, aromatic ring without methyl group vibrate together with $\mathrm{C}_{4}=\mathrm{O}$ to produce frequency at $1626 \mathrm{~cm}^{-1}$ but aromatic ring with methyl group vibrate with $\mathrm{C}_{1}=\mathrm{O}$ to produce it at $1634 \mathrm{~cm}^{-1}$, in both case vibration of aromatic ring is predominant. Hence, we can conclude that addition of methyl group shows direct effect in the weak band. Due to addition of methyl side group, vibration of both aromatic ring is not as homogeneous as AQ but at different frequency, with one predominant than other and mixed with one of the $\mathrm{C}=\mathrm{O}$ mode.

Moreover, in $\mathrm{AQ}_{11,12}$ highly intense band was observed at $1728 \mathrm{~cm}^{-1}$ and cause of this is similar as other two anthraquinones. A vibration of aromatic ring with/without methyl group produced frequency at $1612 / 1641 \mathrm{~cm}^{-1}$ and due to vibration of both aromatic rings a band was produced at $1623 \mathrm{~cm}^{-1}$.

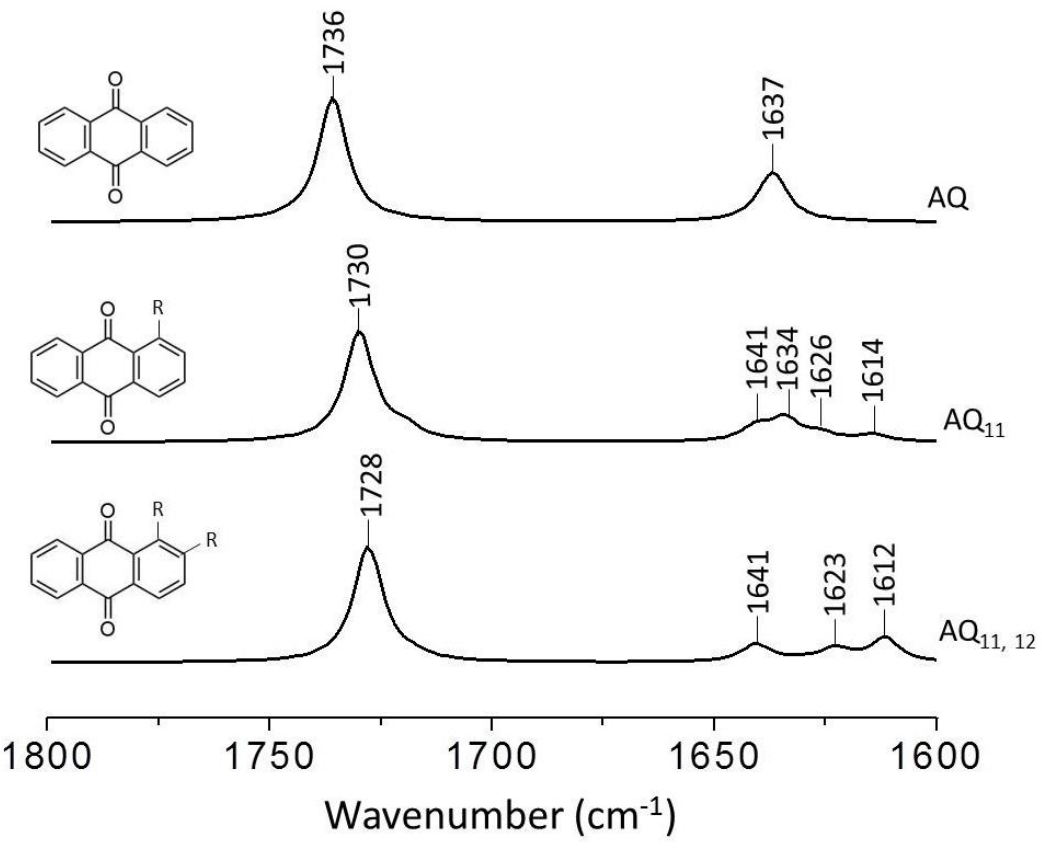

Fig. 10. Calculated IR absorption spectra of $A Q, A Q_{11}$ and $N Q_{11,12}$ in gas phase.

\section{CONCLUSION}

On sequential addition of methyl group (s) to the different carbon positions of naphtho- and anthraquinones model molecules, we concluded that, in NQs, the $\mathrm{CH}_{3}$ substitution on NQ's quinone ring carbon positions to produce MNQ and DMN, has shown single intense carbonyl band and cause of this band is due to asymmetric carbonyl mode of vibration. Importantly, presence of one methyl group lowers down frequency (in average) of the band by $5 \mathrm{~cm}^{-1}$. However, such addition on the aromatic ring results into mix effect. On this particular ring substitution, two types of carbonyl bands, which are couple and uncouple, were observed. For the further exploration of splitting effect in the carbonyl band, we added one or two methyl group (s) on $\mathrm{C}_{7}, \mathrm{C}_{8}, \mathrm{C}_{9}$, and $\mathrm{C}_{10}$ positions of NQ obtaining four or six model molecules. From 
this we figured out that $\mathrm{C}_{7}$ and $\mathrm{C}_{10}$ substitutions are more sensitive to the $\mathrm{C}=\mathrm{O}$ mode i.e. it leads to the breaking the intense band up into $\mathrm{C}_{1}=\mathrm{O}$ and $\mathrm{C}_{4}=\mathrm{O}$ stretching mode. Furthermore, the sequential addition of methyl group on AQ, although leads to the lowering in frequency, has no splitting effect on the intense carbonyl mode of vibration. Such substitution on $A Q$ to get $A Q_{11}$ and $A Q_{11,12}$ lower down frequency of the intense band respectively by 6 and $8 \mathrm{~cm}^{-1}$.

\section{ACKNOWLEDGEMENTS}

Authors are acknowledged the Central Department of Physics for providing Gaussian 03 and computational facilities.

\section{REFERENCES}

Bandaranayake, K. M. P.; Wang, R. and Hastings, G. (2006). Modification of the Phylloquinone in the $\mathrm{A}_{1}$ Binding Site in Photosystem I Studied Using Time-Resolved FTIR Difference Spectroscopy and Density Functional Theory, Biochemistry, 45 (13): 4121-4127.

Banwell, C. N. and McCash, E. M. (1999). Fundamental of Molecular Spectroscopy, Tata McGraw-Hill Publishing Company Limited, New Delhi.

Bellamy, L. J. (1980). The Infrared Spectra of Complex Molecules, Chapman and Hall, London and New York.

Coates, J. (2000). Interpretation of Infrared Spectra, A Practical Approach, John Willy \& Sons Ltd., Chichester.

Frisch, M. J.; Trucks, G. W.; Schlegel, H. B.; Scuseria, G. E.; Robb, M. A.; Cheeseman, J. R. et al. (2004). Gaussian, Inc., Wallingford CT.

Guin, P. S.; Das, S. and Mandal, P. C. (2011). Electrochemical Reduction of Quinones in Different Media: A Review, International Journal of Electrochemistry, 2011: 1-22.
Hucke, O.; Schmid R. and Labahn, A. (2002). Exploring the primary electron acceptor $\left(\mathrm{Q}_{\mathrm{A}}\right)$-site of the bacterial reaction center from Rhodobactersphaeroids, The FEBS Journal, 269 (4): 1096-1108.

Ke, B. (2001). Photosynthesis: Photobiochemistry and Photobiophysics, Kluwer Academic.

Lamichhane, H. P. (2011). Calculated Vibrational Properties of Quinones in Photosynthetic Reaction Centers, $\mathrm{PhD}$ Thesis, Georgia State University, USA.

Nonella, M. and Brandli, C. (1996). Density Functional Investigation of MethoxySubstituted $\mathrm{p}$ Benzoquinones: Confromational Analysis and Harmonic Force Field of 2-methoxy- and 2, 3 Dimethoxy-1, 4-Benzoqinone, The Journal of Physical Chemistry, 100 (34): 1454914559.

Okamura, M. Y.; Paddock, M. L.; Graige, M.S. and Feher, G. (2000). Proton and electron transfer in bacterial reaction centers, Biochemia et Biophysica Acta (BBA)Bioenergetics, 1458 (1): 148-163.

Patai, S. (1974). The Chemistry of Quinonoid Compounds, John Willey \& Sons, New York. Publishers.

Raut, N. and Lamichhane, H. P. (2016). Effect of Additional Methyl Groups on the Carbonyl Bands of Naphthoquinone Family, presentation in $33^{\text {rd }}$ general convention of Nepal Physical Society.

Socrates, G. (2004). Infrared and Raman Characteristic group Frequencies: Table and Chart, John Wiley \& Sons.

Trumpower, B. L. (1982). Functions of Quinones in Energy Converting Systems, Academic, New.

Wakil, S. J. (1970). Lipid Metabolism, Academic Press, New York. 